\title{
Psicooncología
}

ISSN: 1696-7240

\section{Factor structure, internal consistency and distribution of Female Sexual Function Index among Mexican women with early diagnostic of breast cancer}

Melina Miaja Avila ${ }^{1}$; José Moral de la Rubia ${ }^{2 *}$; Alan Fonseca ${ }^{3}$; Marlid Cruz Ramos ${ }^{4}$ Cynthia Villarreal Garza ${ }^{5}$; Andrea Becerril Gaitán ${ }^{6}$; Bryan Francisco Vaca Cartagena ${ }^{7}$; Ana Sofía Ferrigno Guajardo ${ }^{8}$

Recibido: 28 de abril de 2021 / Aceptado 20 de agosto de 2021

Abstract. Background: Female Sexual Dysfunction (FSD) occurs frequently in women with breast cancer due to oncologic treatments. It is essential to have a validated instrument to diagnose and quantify FSD in this population accurately. Objective: To validate the Female Sexual Function Index (FSFI). Method: The FSFI was applied to 272 sexually active Mexican women with recent diagnosis of breast cancer who had not initiated systemic cancer treatment. Results: The FSFI six-factor model is valid by confirmatory factor analysis, and the inventory and its factors have adequate internal consistency reliability. Conclusions: This study provides enough evidence about the reliability and factor structure of the FSFI questionnaire in the context of breast cancer clinical practice in Mexico.

1 Melina Miaja Avila Centro de Cáncer de Mama, Tecnológico de Monterrey, Monterrey. Joven \& Fuerte: Programa para la Atencion e Investigación de Mujeres Jóvenes con Cáncer de Mama, Ciudad de México, México. E-mail: miajaam@live.com.mx

2 José Moral de la Rubia. School of Psychology, Autonomous University of Nuevo León, Monterrey. Dr. Carlos Canseco 110. Col. Mitras Centro. C. P. 64460. Monterrey, NL., México. Tel. (81) 833382 33. Ext. 423

E-mail: josemoral@hotmail.com

3 Alan Fonseca. Departamento de Tumores Mamarios y Departamento de Investigación, Instituto Nacional de Cancerología, Ciudad de México. Joven \& Fuerte: Programa para la Atención e Investigación de Mujeres Jóvenes con Cáncer de Mama, Ciudad de México, México.

E-mail: afonseca@globalcancerinstitute.org

4 Marlid Cruz Ramos. Departamento de Tumores Mamarios y Departamento de Investigación, Instituto Nacional de Cancerología, Ciudad de México. Joven \& Fuerte: Programa para la Atención e Investigación de Mujeres Jóvenes con Cáncer de Mama, Ciudad de México. Cátedras CONACYT, Instituto Nacional de Cancerología, Ciudad de México. Mexico.

E-mail: marlid.cruz@gmail.com

5 Cynthia Villarreal Garza. Centro de Cancer de Mama, Tecnologico de Monterrey. Monterrey. Joven \& Fuerte: Programa para la Atención e Investigación de Mujeres Jóvenes con Cáncer de Mama, Ciudad de México. México.

E-mail: cynthiavg@gmail.com

6 Andrea Becerril Gaitán. Medical School, Tecnológico de Monterrey. Monterrey . México

E-mail: bgandy1310@gmail.com

7 Bryan Francisco Vaca Cartagena. Medical School, Tecnológico de Monterrey. Monterrey. México. E-mail: bryanvaca96@gmail.com

8 Ana Sofía Ferrigno Guajardo. Medical School, Tecnológico de Monterrey. Monterrey. México.

E-mail: ana.ferrigno@gmail.com

* Dirección de dorrespondencia: José Moral de la Rubia. School of Psychology, Autonomous University of Nuevo León, Monterrey. Dr. Carlos Canseco 110. Col. Mitras Centro. C. P. 64460. Monterrey, NL., México. E-mail: jose_moral@hotmail.com 
Keywords: Sexual satisfaction, female sexual function, breast cancer, Mexican Validation, factor structure.

[es] Estructura factorial, consistencia interna y distribución del Índice de Función Sexual Femenina entre mujeres mexicanas con diagnóstico temprano de cáncer de mama

Resumen. Antecedentes: La disfunción sexual femenina (FSD) ocurre con frecuencia en mujeres con cáncer de mama debido a los tratamientos oncológicos. Es fundamental contar con un instrumento validado para diagnosticar y cuantificar la FSD en esta población con precisión. Objetivo Validar el Índice de Función Sexual Femenina (FSFI). Método: El FSFI se aplicó a 272 mujeres mexicanas sexualmente activas con diagnóstico reciente de cáncer de mama que no habían iniciado tratamiento oncológico sistémico. Resultados: El modelo de seis factores de la FSFI se validó por análisis factorial confirmatorio y el inventario y sus factores tienen una fiabilidad de consistencia interna adecuada. Conclusiones: Este estudio proporciona suficiente evidencia sobre la confiabilidad y la estructura factorial del cuestionario FSFI en el contexto de la práctica clínica del cáncer de mama en México.

Palabras clave: Satisfacción sexual, función sexual femenina, cáncer de mama, validación mexicana, estructura factorial

Sumario: 1. Introduction 2. Materials and Methods 3. Data analysis 4. Results 5. Discussion 6. References

Como citar: Miaja Avila M, Moral de la Rubia J, Fonseca A, Cruz Ramos M, Villarreal Garza C, Becerril Gaitán A, Francisco Vaca Cartagena B, Ferrigno Guajardo AS. Factor structure, internal consistency and distribution of Female Sexual Function Index among Mexican women with early diagnostic of breast cancer. Psicooncología 2021; 18: 293-316, https://dx.doi.org/10.5209/psic.77755

\section{Introduction}

\section{Female Sexual dysfunction and breast cancer}

Female Sexual Dysfunction (FSD) has been reported in 34.7\% to $92 \%$ of women with breast cancer, with the average prevalence estimated to be higher than $60 \%{ }^{(1)}$. When comparing the sexual function between young and older women diagnosed with breast cancer, a higher proportion of young women report FSD ${ }^{(2)}$. In fact, FSD is one of the most frequently unaddressed problems in this age group ${ }^{(3)}$. The increased severity of symptoms of FSD in young women may be due to the induction of early menopause as a side effect of cancer treatment ${ }^{(4-6)}$.

It is important to note that during routine medical appointments, FSD is one the least-addressed consequences of oncologic treatment, despite its high prevalence and its negative impact on quality of life. In this sense, Reese et al. ${ }^{(7)}$ found that only $28 \%$ of healthcare providers informed women with cancer about the possibility of FSD secondary to oncologic treatment, and only $21 \%$ identified sexual concerns in their patients. Furthermore, treatment for the sexual problems that were recognized using the National Comprehensive Cancer Network (NCCN) Sexual Function Guidelines was offered to only $17 \%$ of patients ${ }^{(7)}$. According to Bober et al. ${ }^{(8)}$ a "conspiracy of silence" between healthcare providers and patients exists regarding sexuality and 
FSD. This was illustrated by Kedde et al. ${ }^{(4)}$ who reported that 6 out of 10 young women with breast cancer and FSD, did not seek medical attention for this issue.

\section{The Female Sexual Function Index (FSFI): an instrument to evaluate FSD}

There are several instruments with good psychometric properties that reduce the communication barriers between doctors and patients and facilitate the detection of $\mathrm{FSD}^{(1)}$. One of the instruments that is recommended by the NCCN is the FSFI. It should be noted that the study by Baser et al. ${ }^{(9)}$ prompted the NCCN to recommend the use of this instrument to assess sexual function among women diagnosed with cancer.

The FSFI is a 19-item, self-report questionnaire that measures female FSD in a multidimensional way. Its final version arises from the study by Rosen et al. ${ }^{(10)}$ in which a questionnaire of 30 items was tested in two populations. The first group consisted of 128 women diagnosed with female sexual arousal disorder according to the criteria of the Diagnostic and Statistical Manual of mental disorders, 4th edition ${ }^{(11)}$. The second group consisted of 131 healthy women. The FSFI was designed to assess 6 domains of female sexual function which include desire, arousal, lubrication, orgasm, satisfaction, and pain. 11 of the 30 items that were initially included, were removed through expert judgment and content ambiguity analysis. The internal consistency reliability values of the 6 expected factors were good in both groups and in the pooled sample (Cronbach's $\alpha \geq 0.82$ ). Based on the Kaiser criterion both in the 2 groups of women and in the joint sample, the number of factors was 4 with the 19 selected items. In the group of 128 women with FSD, when 5 factors were extracted through a principal component analysis, the expected configuration was obtained in the orthogonally rotated factor matrix, except for the two items of sexual desire and the four items of sexual arousal. These 6 items were grouped in the same factor. Therefore, it was not separated according to the two expected factors. In the group of 131 healthy women, when 5 or 6 factors were extracted and the factor matrix was rotated, the expected structure was not reproduced. Based on reliability data and theoretical-practical advantages, Rosen et al. ${ }^{(10)}$ suggested that it is better to separate the factors of sexual desire ( 2 items) and sexual arousal (4 items), and to maintain the 6-factor structure designed with the 19 selected items ${ }^{(10)}$.

Wiegel et al. ${ }^{(12)}$ conducted a study that included 568 American women to establish a threshold to diagnose FSD using the FSFI questionnaire. They determined that a threshold score of 26.55 was optimal to recognize women with FSD. With this cut-off value, they were able to correctly classify $70.7 \%$ of women with hypoactive sexual desire problems, lack of sexual arousal, anorgasmia, and dyspareunia as having FSD, and exclude a sexual disorder in $88.1 \%$ of healthy women.

\section{Properties of FSFI in women with cancer}

The metric properties of the FSFI have been studied in women with cancer. In a group of 181 female American cancer survivors, Baser et al ${ }^{(9)}$ found out that the 5 -factor structure explained $81.4 \%$ of the total variance, as assessed by a principal components' analysis. This 5-factor structure was equivalent to the original factor structure described in the original study by Rosen et al. ${ }^{(10)}$ the internal consistency values were high (Cronbach's overall $\alpha=0.94$ and ranged from 0.85 to 0.94 for the 5 factors). The FSFI scores demonstrated convergent validity by correlating 
inversely to menopausal symptoms, reproductive problems, and depression; and correlating directly to quality of life.

On the other hand, Bartula \& Sherman ${ }^{(13)}$ studied the factor structure of the FSFI in a sample of 399 sexually active Australian women diagnosed with breast cancer. They used confirmatory factor analysis through the maximum likelihood method. They found that the correlated 6-factor model, excluding item 14 (emotional closeness to partner), showed the best fit to the data compared to the models of 1 factor, 5 correlated factors, and 5 or 6 lower-order factors hierarchized to 1 higherorder factor. The internal consistency reliability values for the 6-factor structure (without the item number 14 in the sexual satisfaction factor) ranged from good (Cronbach's $\alpha=0.89$ for Sexual Satisfaction) to excellent (Cronbach's $\alpha=0.96$ for Vaginal Lubrication) and those for 3-week temporal stability ranged from $r_{t 122}=0.75$ for dyspareunia to $r_{t 1 t 2}=0.86$ for sexual desire.

\section{FSFI properties in Spanish-speaking populations}

The FSFI is available in Spanish, however it has not been validated for patients with cancer. Blümel et al. ${ }^{(14)}$ translated and validated this instrument in a Chilean sample. A total of 371 sexually active healthy women were evaluated and high internal consistency values (Cronbach's $\alpha=0.71$ to 0.88 ) for the 6 domains, proposed by Rosen et al. ${ }^{(10)}$ were demonstrated. However, the 6 -factor model was not tested.

In Colombia, Vallejo-Medina et al. ${ }^{(15)}$ translated the FSFI for its validation in the general population. The 6-domain-model was reproduced using a principal component analysis and oblique rotation. The internal consistency of the factors was good (Cronbach's $\alpha=0.84$ to 0.89 ).

In Spain, Sánchez-Sánchez et al. ${ }^{(16)}$ translated and validated the FSFI using two samples, the first one included women from the general population and the other one included women with pelvic floor disorders. They obtained excellent short-term temporal stability values (2-4 weeks) (intraclass correlation coefficient [ICC] $>0.90$ ) and internal consistency values that ranged from acceptable (Cronbach's $\alpha \geq 0.70$ ) to good (Cronbach's $\alpha \geq 0.80$ ) for the total score and its factors. Using the principal component analysis, the 6-domain-model was reproduced and showed adequate discriminant validity (Pearson's $r^{2}$ or shared variance from 0.13 to 0.44 ).

\section{Problem Statement}

Female sexual dysfunction is a common adverse effect of breast cancer treatments, however there is few information in Latin-American patients. Another concern is the instrument to measure the FSD in this population. Even though the FSFI has been validated in Spanish, this instrument has not been validated in female cancer patients.

Regarding the FSFI, Baser et al. ${ }^{(9)}$, carried out a study in women with cancer that showed weaknesses in its factor analysis, because they used the principal component analysis to validate a theoretical model. Bartula \& Sherman ${ }^{(17)}$, also overcame these weaknesses by using a confirmatory factor analysis and defining two hierarchical models that theoretically justify the syndrome construct and the calculation of a total score. However, no bifactor model was specified when this type of model justifies the syndrome concept, having more flexible assumptions than the hierarchical models and usually yields better fit values than this latter model ${ }^{(18)}$. In a systematic review of 
83 studies on the metric properties of the 19-item FSFI, concluded that the evidence of internal consistency reliability is enough and of moderate quality, but that the evidence of its structural validity is inconsistent and of low quality, therefore requiring further research. Consequently, aspects of psychometric validation remain pending ${ }^{(19)}$.

The purpose of this study is to validate the FSFI in young Mexican women with breast cancer, using the Spanish translation made by Blümel et al. ${ }^{(14)}$. Our four specific objectives are: 1) to test the 6 and 5 factor models; 2) verify the internal consistency reliability of the 19 items (general factor) and the 5 or 6 content domains (specific factors); 3 ) describe the distributions of the total score and its 5 or 6 factors; and, 4) estimate the prevalence of FSD in our sample using the cut-off point of $\leq$ 26.55 for FSD.

\section{Materials and Methods}

\section{Type of study and design}

Based on our objectives, this study is a validation study of a measurement instrument in breast cancer Mexican women. The data analyzed in this validation study are part of the baseline phase of a multicenter longitudinal prospective study to evaluate the application in Mexico of the Young and Strong Program for Young Women with Breast Cancer developed originally by the Dana-Farber Cancer Institute. It should be noted that the data for this article was collected from June 2014 to December 2019 and corresponds to a cross section (measurements in a single time per participant).

\section{Subjects and data collection}

Females between 18 to 44 years old with a recent diagnosis of breast cancer. The exclusion criteria were: illiteracy or having an intellectual disability that impedes the patient from reading and understanding the questions on the self-report questionnaire, and not being sexually active (to not have had sexual intercourse in the last four weeks, which is the time-frame evaluated by the FSFI). Patients were also eliminated from the study if they didn't answer all the questions of the measurement instrument.

A total of 441 Mexican women diagnosed with breast cancer at the baseline stage of their treatment were screened for the eligibility criteria. Patients in their first oncology appointment were asked to participate in this study. They had to answer an online questionnaire within a maximum period of three months from the diagnosis made by an oncologist. Patients' healthcare institutions and types of health insurance are described in table 1 . All patients signed a written informed consent and none of them refused to participate. Due to sexual inactivity in the last four weeks, 169 out of 441 screened women were excluded from the study. There were no cases of intellectual disabilities. The sample size was determined by having at least five participants per parameter to be estimated in the factor models. The ratio was five participants per parameter to be estimated in the two bifactor models and in the correlated 6-factor model, and six participants per parameter to be estimated in the two hierarchical models and in the correlated 5-factor model. The sociodemographic data to describe the sample was taken from the medical records and the missing data was excluded from the descriptive analysis. 
Table 1. Healthcare institutions and type of health insurance

\begin{tabular}{|c|c|c|c|c|c|c|c|}
\hline \multirow{2}{*}{$\begin{array}{l}\text { Variable } \\
\text { label }\end{array}$} & \multirow[t]{2}{*}{ Value label } & \multicolumn{2}{|c|}{$\begin{array}{l}\text { Included } \\
\text { patients }\end{array}$} & \multicolumn{2}{|c|}{$\begin{array}{l}\text { Excluded } \\
\text { patients }\end{array}$} & \multicolumn{2}{|c|}{ Total } \\
\hline & & $\mathrm{n}$ & $\%$ & $\mathrm{n}$ & $\%$ & $\mathrm{n}$ & $\%$ \\
\hline \multirow{8}{*}{$\begin{array}{l}\text { Healthcare } \\
\text { institution }\end{array}$} & $\begin{array}{l}\text { National Institute } \\
\text { of Cancerology }\end{array}$ & 183 & $67,3 \%$ & 115 & $68 \%$ & 298 & $67,6 \%$ \\
\hline & San José Hospital & 61 & $22,4 \%$ & 34 & $20,1 \%$ & 95 & $21,5 \%$ \\
\hline & $\begin{array}{c}\text { Zambrano Hellion } \\
\text { Hospital }\end{array}$ & 7 & $2,6 \%$ & 5 & $3 \%$ & 12 & $2,7 \%$ \\
\hline & $\begin{array}{l}\text { Chihuahua State } \\
\text { Cancer Center }\end{array}$ & 3 & $1,1 \%$ & 7 & $4,1 \%$ & 10 & $2,3 \%$ \\
\hline & $\begin{array}{c}\text { Toluca State Cancer } \\
\text { Center }\end{array}$ & 9 & $3,3 \%$ & 4 & $2,4 \%$ & 13 & $2,9 \%$ \\
\hline & $\begin{array}{c}\text { Tijuana General } \\
\text { Hospital }\end{array}$ & 6 & $2,2 \%$ & 3 & $1,8 \%$ & 9 & $2 \%$ \\
\hline & $\begin{array}{c}\text { Bajío High S. Regional } \\
\text { Hospital }\end{array}$ & 3 & $1,1 \%$ & 1 & $0,6 \%$ & 4 & $0,9 \%$ \\
\hline & Total & 272 & $100 \%$ & 169 & $100 \%$ & 441 & $100 \%$ \\
\hline \multirow{5}{*}{$\begin{array}{c}\text { Health } \\
\text { insurance }\end{array}$} & Public health insurance & 225 & $87,2 \%$ & 142 & $88,2 \%$ & 367 & $87,6 \%$ \\
\hline & None & 25 & $9,7 \%$ & 11 & $6,8 \%$ & 36 & $8,6 \%$ \\
\hline & Private health insurance & 8 & $3,1 \%$ & 8 & $5 \%$ & 16 & $3,8 \%$ \\
\hline & Total & 258 & $100 \%$ & 161 & $100 \%$ & 419 & $100 \%$ \\
\hline & Missing value & 14 & & 8 & & 22 & \\
\hline
\end{tabular}

\section{Measures}

The translated FSFI version used in this study consists of 19 Likert scale survey questions and uses five ordinal categories. People are asked whether they were sexually active four weeks prior to the evaluation and each item is scored from 1 to 5 .

Rosen et al. ${ }^{(10)}$ evaluated two groups, the first one consisted of 128 women with sexual dysfunction and the other consisted of 131 healthy women that matched their age (Cronbach's $\alpha=0.97)$. They found excellent internal consistency for the following domains: sexual desire (questions 1,2), sexual arousal (questions 3-6), vaginal lubrication (questions 7-10), orgasm (questions 11-13), and pain during sex (questions 17-19), with the following Cronbach's $\alpha=(0.92,0.95,0.96,0.94,0.94)$, respectively.

Higher scores on the FSFI total score and individual dimensions indicated a better sexual function. In order to obtain the FSFI factor scores, we added all the items corresponding to each domain and then multiplied them by a specific factor ratio: 0.6 for sexual desire; 0.4 for orgasm, 0.4 sexual satisfaction, 0.4 for pain; 0.3 for sexual arousal; and 0.3 vaginal lubrication. For the 5 -factor model, the sexual desire and arousal factor, which is made up of 6-items (questions 1-6), is multiplied 
by 0.2 . This transforms the range of scores for each factor to a continuous scale, ranging from 1.2 to 6 . The total score of the FSFI is obtained by adding the scores of the 6 or 5 individual factors. Hence, the FSFI total score for sexually active women ranges from 7.2 to 36 both in the 5-factor model and 6-factor models.

\section{Data analysis}

Factor analysis was used for testing the three types of models proposed (5 or 6 domains). The discrepancy function was optimized through Free-Scale Least Squares (FSLS). A moment matrix (arithmetic mean, standard deviation and polychoric correlation) was used as input data. This method was chosen because it suits ordinal variables, such as items with Likert-type scales. Standard error estimation and significance testing were performed using the Bias-Corrected Percentile (BCP) method with the extraction of 2,000 bootstrap samples. The data was assessed using eight indices: relative chi-square $(\chi 2 / \mathrm{df})$, goodness-of-fit Index (GFI), adjusted goodness-of-fit Index (AGFI), normed fit index (NFI), comparative fit index (CFI), relative fit index (RFI), standardized root-mean-squared residual (SRMR), and root-mean-square error of approximation (RMSEA). It was set that values $\geq 0.95$ of the following indices $\left(\chi^{2} /\right.$ df $<2$, GFI, NFI, CFI and RFI) reflected a close fit; as well as AGFI $\geq 0.90$, SRMR and RMSEA $\leq 0.05$. Values $\geq 0.90$ for $(\chi 2 / \mathrm{df}<3$, GFI, NFI, CFI and RFI reflected an acceptable fit, as well as, AGFI $\geq 0.85$, SRMR $<0.08$ and RMSEA $<0.10$. The equivalence in goodness of fit between the models was tested by the quotient between chi-square statistic difference and the difference in degrees of freedom $\left(\Delta \chi^{2} / \Delta \mathrm{df}\right)$, difference in akaike information criterion $(\triangle \mathrm{AIC})$, as well as by the difference in GFI $(\triangle \mathrm{GFI}), \mathrm{NFI}(\triangle \mathrm{NFI})$, and CFI $(\triangle \mathrm{CFI})$, SRMR $(\triangle \mathrm{SRMR})$, and RMSEA $(\triangle \mathrm{RMSEA})$ statistics. Absolutes values of $\left|\chi^{2 / \Delta \mathrm{df}}\right| \leq 2,|\Delta \mathrm{AIC}|<4$, and $|\Delta \mathrm{GFI}|,|\Delta \mathrm{NFI}|$, $|\Delta \mathrm{CFI}|,|\Delta \mathrm{RFI}|,|\Delta \mathrm{SRMR}|$ and $|\Delta \mathrm{RMSEA}| \leq 0.01$ reflected an equivalence in goodness of fit. The parsimony of the model was assessed using the Jame-MulaikBrett's parsimony ratio (PR). A PR value of $<1 / 4$ was considered as low parsimony, and if the value was $\geq 3 / 4$ it was considered as high parsimony. Three parsimonious indices were calculated: parsimonious normed fit index (PNFI), parsimonious comparative fit index (PCFI), and parsimonious goodness-of-fit index (PGFI). Values $\geq 0.80$ for PNFI and PCFI reflected a good relationship between fit and parsimony, as well as PGFI $\geq 0.70$. Values $<0.60$ for PNFI and PCFI reflected a poor relationship between fit and parsimony, as well as PGFI $<0.50$

In the two factor models, the convergent validity was assessed through three criteria: an omega coefficient $(\omega) \geq 0.70$, standardized measurement weights $(\lambda \mathrm{i})$ $\geq 0.50$, and average variance extracted (AVE) $\geq 0.54$ for two indicators, 0.44 for three indicators, 0.37 for four indicators, 0.28 for six indicators, and 0.25 for seven or more indicators. The discriminant validity between factors was assessed through the heterotrait-monotrait ratio of correlations (HTMT) or quotient between the arithmetic mean of the $n * m$ non-redundant correlations of the items crossed between two factors and the geometric mean of the means of the $\left[n^{*}(\mathrm{n}-1)\right] / 2$ or $[\mathrm{m} *(\mathrm{~m}-1)] / 2$ non-redundant correlations between the items of each factor. An HTMT value $\leq 0.85$ was stipulated as a threshold for a good level of discriminant validity, and an HTMT value $\leq 0.90$ as a threshold for an acceptable level of discriminant validity. 
Within each one of the two hierarchical factor models, two sub-models were distinguished. There is a higher order sub-model that corresponds to the direct effect of the general factor on the 5 or 6 hierarchical factors. On the other hand, there are the 5 or 6 lower order sub-models that correspond to the indirect effect of the general factor and the direct effect of the hierarchical factor on the items of a content domain. The convergent validity in the higher order sub-model was assessed using three criteria: $\lambda \mathrm{Fi}, \omega$ coefficient and AVE. The following values showed convergent validity: $\lambda \mathrm{Fi} \geq 0.50, \omega \geq 0.70$, and AVE for 5 factors $\geq 0.32$ and 0.28 for 6 factors. In the 5 or 6 lower-order sub-models, hierarchical omega $\left(\omega h_{-}\right)$, average extracted variance (AVE_) and the proportion of explained common variance (ECV_) attributable to the higher-order general factor (GF) and the hierarchical factor $(\overline{\mathrm{HF}})$ were calculated to assess the contribution of these two types of factors. Values of $\omega \mathrm{h} \_\mathrm{GF}, \omega \mathrm{h} \_\mathrm{HF}, \mathrm{ECV}$ GF and ECV_HF less than 0.10 reflected a trivial relative contribution, values $(\overline{0} .10-0.29)$ a poor contribution, values $(0.30-0.69)$ a substantive contribution, values $(0.70-0.89)$ an excessive contribution, and values $\geq 0.90$ were considered as unitary. Taking into account a minimum value for AVE $(\geq 0.54$ for two indicators, 0.44 for three indicators, 0.37 for four indicators, 0.28 for six indicators, and 0.25 for seven or more indicators) and a contribution of at least $30 \%$, the minimum value of the AVE for the general (AVE_GF) or hierarchical factor (AVE_HF) should be: 0.16 for two indicators, 0.13 for three indicators, 0.11 for four indicators, 0.09 for six indicators, and 0.08 for seven or more. The maximum value that could be reached was 0.70 for a maximum contribution of $70 \%$. A pooled assessment of the 5 or 6 lower order models was also carried out.

In the two bifactor models, the contribution of specific factor (SF) and general factor (GF) in each one of the 5 or 6 content domains was assessed using 6 indices: hierarchical omega related to the specific factor ( $\omega$ h_SF), the general factor ( $\omega \mathrm{h}$ $\mathrm{GF}$ ), explained common variance in relation to the specific factor (ECV_SF) and general factor (ECV_GF), as well as average variance explained by the specific factor (AVE_SF) and the average variance explained by the general factor (AVE GF). Values $(0.30-0.60)$ for the $\omega \mathrm{h}$ and ECV reflected a significant and balance $\bar{d}$ contribution; values $<0.30$ indicate a poor contribution and values $>0.70$ showed an excessive contribution. Taking into account a minimum value for AVE and a contribution of at least $30 \%$, the minimum value of the AVE for the general (AVE_GF) or specific factor (AVE_SF) should be 0.16 for two indicators, 0.13 for three indicators, 0.11 for four indicators, 0.09 for six indicators, and 0.08 for seven or more. The maximum value that could be reached was 0.70 for a maximum contribution of $70 \%$.

The internal consistency reliability of each factor was calculated using the ordinal alpha coefficient (ordinal $\alpha$ ). Ordinal $\alpha$ values $(0.70-0.79),(0.80-0.89),(\geq 0.90)$ reflected an acceptable, good and excellent internal consistency, respectively.

The strength of association between the factors and their effect on three indicators (estimated through standardized measurement weights) was interpreted as follows: $<0.10,0.10-0.29,0.30-0.49,0.50-0.69,0.70-0.89, \geq 0.90$ for trivial, weak, moderate, strong, very strong, and perfect, respectively.

For describing the distributions, the null hypothesis of normal distribution was tested through the D'Agostino-Pearson's K2 test and Kolmogorov-Smirnov's test with the Lilliefors correction. Due to non-compliance with normal distribution, 
the median (Mdn) was used as the central tendency statistic. The equivalence in central tendency among the factors was tested with Friedman's test. The effect size was estimated by Kendall's coefficient of concordance (W). With six degrees of freedom, a value of $\mathrm{W}<0.10,0.10-0.24, \geq 0.25$ was interpreted to reflect a small, medium and large effect size, respectively. Subsequent pairwise comparisons were carried out using Dunn's test.

The equivalence between the expected value of prevalence of FSD and the proportion of cases in the sample was tested with the one-tailed binomial test.

When testing statistical hypotheses, the significance level was set at 0.05 . The calculations were made with the programs SPSS 24, module R version 2.4 for SPSS 24, AMOS 16, and Excel 2013 with the real statistics complement.

\section{Results}

\section{Sample Description}

When comparing the sample of sexually active women in the last four weeks with the sexually inactive women, the distribution of frequencies of the seven healthcare institutions was statistically equivalent between the two samples (Fisher's exact test $=5.06$, two-tailed $\mathrm{p}$-value $=0.539$ ), as well as the type of health insurance they had $\left(\chi^{2}[2, \mathrm{~N}=419]=1.86\right.$, right tail $\mathrm{p}$-value $\left.=0.395\right)($ Table 1$)$. Table 2 shows the sociodemographic and clinical description of the analyzed sample. There were no significant differences in means of age (Student's t-test: $t$ [421] $=0.70$, 2-tailed $p$-value $=0.485)$ or in medians of education level (Mann-Whitney's $U$ test: $Z_{U}=$ $-1.15,2$-tailed $p$-value $=0.250$ ). When comparing the sexually active women with the women that reported no sexual intercourse in the last four weeks, a higher proportion were married (52.9\% versus $30.4 \%$ ) or lived in a consensual union $(21.8 \%$ versus $12.4 \%)$, and less women were single ( $20.6 \%$ versus $47.8 \%)$. The differences in the distribution of marital status between both groups were statistically significant $(\chi 2[4$, $\mathrm{N}=418]=43.70$, right tail $\mathrm{p}$-value $<0.001$ ), with a moderate association between being married and sexually active (Cramer's $\mathrm{V}=0.323$ ).

Sexually active women had a significantly higher number of children $(\mathrm{M}=$ 1.83, 95\% CI: $1.67,1.98)$ ( $[341]=-2.85, \mathrm{p}=0.005$; Hedges-Olkin's $\mathrm{g}=-0.29$, $95 \%$ CI: $-0.48,-0.09)$ than women without sexual activity $(\mathrm{M}=1.47,95 \% \mathrm{CI}$ : $1.27,1.66)$. Regarding occupation $\left(\chi^{2}[5, \mathrm{~N}=417]=14.78, \mathrm{p}=0.011\right.$, Cramer's $\mathrm{V}=0.19)$, there were more housewives $(58.9 \%)$ and fewer part-time jobs $(15.5 \%)$ among sexually active women than among women without sexual activity $(45.9 \%$ and $23.3 \%$, respectively). There was also a significant difference in the cancer stage (Mann-Whitney's $U$ test: $Z_{U}=-1.99,2$-tailed $p$-value $=0.046$ ) with a small effect of the cancer stage on being sexually active in the four weeks prior to the survey (Rosenthal's $r^{2}>0.010$ ). The mean rank (MR) of the stage of cancer development was lower in the patients with sexual activity in the last four weeks $(M R=196.77)$ than in the patients without sexual activity $(M R=220.33)$. 
Table 2. Frequency distributions of sociodemographic and clinical variables

\begin{tabular}{|c|c|c|c|c|}
\hline $\begin{array}{c}\text { Variable } \\
\text { label }\end{array}$ & Value label & $\mathrm{n}$ & Percentage & $\begin{array}{l}\text { Cumulative } \\
\text { percentage }\end{array}$ \\
\hline \multirow{6}{*}{ Age } & $19-24$ & 11 & $4 \%$ & $4 \%$ \\
\hline & $25-29$ & 32 & $11,8 \%$ & $15,8 \%$ \\
\hline & $30-34$ & 70 & $25,7 \%$ & $41,5 \%$ \\
\hline & $35-39$ & 120 & $44,1 \%$ & $85,7 \%$ \\
\hline & $40-44$ & 39 & $14,3 \%$ & $100 \%$ \\
\hline & Total & 272 & $100 \%$ & \\
\hline \multirow{8}{*}{$\begin{array}{l}\text { Education } \\
\text { level }\end{array}$} & Elementary school & 20 & $7,8 \%$ & $7,8 \%$ \\
\hline & Middle school & 63 & $24,5 \%$ & $32,3 \%$ \\
\hline & High school & 60 & $23,3 \%$ & $55,6 \%$ \\
\hline & Vocational school & 33 & $12,8 \%$ & $68,5 \%$ \\
\hline & Bachelor's degree & 69 & $26,8 \%$ & $95,3 \%$ \\
\hline & Postgraduate education & 12 & $4,7 \%$ & $100 \%$ \\
\hline & Total & 257 & $100 \%$ & \\
\hline & Missing value & 15 & & \\
\hline \multirow{7}{*}{$\begin{array}{l}\text { Marital } \\
\text { status }\end{array}$} & Married & 136 & $52,9 \%$ & \\
\hline & Consensual union & 56 & $21,8 \%$ & \\
\hline & Single & 53 & $20,6 \%$ & \\
\hline & Divorced or separated & 11 & $4,3 \%$ & \\
\hline & Widow & 1 & $0,4 \%$ & \\
\hline & Total & 257 & $100 \%$ & \\
\hline & Missing value & 15 & & \\
\hline \multirow{7}{*}{$\begin{array}{c}\text { Number } \\
\text { of } \\
\text { children }\end{array}$} & 0 & 47 & $18,2 \%$ & $18,2 \%$ \\
\hline & 1 & 52 & $20,2 \%$ & $38,4 \%$ \\
\hline & 2 & 87 & $33,7 \%$ & $72,1 \%$ \\
\hline & 3 & 51 & $19,8 \%$ & $91,9 \%$ \\
\hline & $4-6$ & 21 & $8,1 \%$ & $100 \%$ \\
\hline & Total & 258 & $100 \%$ & \\
\hline & Missing value & 14 & & \\
\hline \multirow{8}{*}{ Occupation } & Housewife & 152 & $58,9 \%$ & \\
\hline & Half-time job & 40 & $15,5 \%$ & \\
\hline & Full-time job & 38 & $14,7 \%$ & \\
\hline & Unemployed & 11 & $4,3 \%$ & \\
\hline & Medical incapacity & 9 & $3,5 \%$ & \\
\hline & Student & 8 & $3,1 \%$ & \\
\hline & Total & 258 & $100 \%$ & \\
\hline & Missing value & 14 & & \\
\hline
\end{tabular}




\begin{tabular}{ccccc}
\hline $\begin{array}{c}\text { Variable } \\
\text { label }\end{array}$ & Value label & $\mathrm{n}$ & Percentage & $\begin{array}{c}\text { Cumulative } \\
\text { percentage }\end{array}$ \\
\hline & 0 & 5 & $2 \%$ & $2 \%$ \\
& IA & 28 & $11,2 \%$ & $13,2 \%$ \\
& IIA & 63 & $25,2 \%$ & $38,4 \%$ \\
Cancer & IIB & 54 & $21,6 \%$ & $60 \%$ \\
& IIIA & 48 & $19,2 \%$ & $79,2 \%$ \\
& IIIB & 16 & $6,4 \%$ & $85,6 \%$ \\
& IIIC & 14 & $5,6 \%$ & $91,2 \%$ \\
& IV & 22 & $8,8 \%$ & $100 \%$ \\
& Total & 250 & $100 \%$ & \\
& Missing value & 22 & & \\
\hline
\end{tabular}

Note. Sociodemographic data was taken from the patient's medical record. Therefore, the missing values are the consequence that this data was missing from the file. Cancer stage: 0 (T0 = noninvasive ductal carcinoma in situ, $\mathrm{N} 0=$ absence or cancer with a size $<0.2 \mathrm{~mm}$ in the mammary or axillary lymph nodes, and M0 = no metastasis), IA (T1 = invasive breast tumor 1 to $20 \mathrm{~mm}$ in size, N0, and M0), IIA (T0, N1 = 1 to 3 internal mammary or axillary lymph nodes invaded by cancer, and M0; T1, N1, and M0; as well as T2 = invasive breast tumor 20 to $50 \mathrm{~mm}$ in size, N0, and M0); IIB (T2, N1, and M0; as well as T3 = invasive breast tumor with a size $>50 \mathrm{~mm}$, N0, and M0), IIIA (T0, N2, and M0; $\mathrm{T} 1, \mathrm{~N} 2=4$ to 9 internal mammary or axillary lymph glands invaded by cancer, and M0; T2, N2, and M0; T3, N1, and M0; as well as T3, N2, and M0): IIIB (T4 = the tumor has grown to affect the chest wall, skin, or is inflammatory, N0, and M0; T4, N1, and M0; as well as T4, N2, and M0); IIIC (any T, N3 = 10 or more internal mammary or axillary lymph nodes invaded by cancer, and M0), IV (any T, any N, and M1 = metastasis to another part of the body).

\section{Model testing and reliability, convergent and discriminant validity of their factors}

Three types of models were used (correlated factors model [CFM-], hierarchical factors model [HM-], and bifactor model [BM-]) for the 5 and 6 domains. Table 3 shows the fit indices, parsimony ratio, and parsimonious fit indices (relationship between fit and parsimony) of these six models. Table 4 shows the goodness of fit between the two models with the best fit (BM-5 and CFM-6) is compared with the remaining models. Tables 5 and 6 show the internal consistency reliability, as well as convergent and discriminant validity of the two correlated-factor models (CFM-5 and CFM-6).

Table 3. Fit indices

\begin{tabular}{ccccccccc}
\hline \multirow{2}{*}{ Indices } & \multicolumn{2}{c}{ Thresholds } & \multicolumn{7}{c}{ Factor models } \\
\cline { 2 - 8 } & Close & Bad & CFM-5 & HM-5 & BM-5 & CFM-6 & HM-6 & BM-6 \\
\hline$\chi^{2}$ & & & 312.192 & 368.253 & 179.550 & 279.222 & 407.175 & 343.979 \\
df & & & 142 & 147 & 133 & 137 & 146 & 135 \\
$\chi^{2} /$ df & $\leq 2$ & $>3$ & 2,199 & 2,505 & 1,350 & 2,038 & 2,789 & 2,548 \\
\hline GFI & $\geq 0,95$ & $<0,85$ & 0,979 & 0,975 & 0,988 & 0,981 & 0,972 & 0,976
\end{tabular}




\begin{tabular}{ccccccccc}
\hline \multirow{2}{*}{ Indices } & \multicolumn{2}{c}{ Thresholds } & \multicolumn{7}{c}{ Factor models } \\
\cline { 2 - 9 } & Close & Bad & CFM-5 & HM-5 & BM-5 & CFM-6 & HM-6 & BM-6 \\
\hline AGFI & $\geq 0,90$ & $<0,80$ & 0,971 & 0,967 & 0,982 & 0,973 & 0,964 & 0,967 \\
NFI & $\geq 0,90$ & $<0,80$ & 0,974 & 0,969 & 0,985 & 0,977 & 0,966 & 0,971 \\
CFI & $\geq 0,90$ & $<0,80$ & 0,986 & 0,981 & 0,996 & 0,988 & 0,978 & 0,982 \\
RFI & $\geq 0,90$ & $<0,80$ & 0,969 & 0,964 & 0,981 & 0,971 & 0,960 & 0,964 \\
RMSEA & $\leq 0,5$ & $>0,075$ & 0,067 & 0,075 & 0,036 & 0,062 & 0,081 & 0,076 \\
SRMR & $\leq 0,5$ & $>0,099$ & 0,078 & 0,085 & 0,059 & 0,074 & 0,089 & 0,082 \\
AIC & & & 408,192 & 454,253 & 293,550 & 385,222 & 495,175 & 453,979 \\
PR & $\mathrm{A} \geq 3 / 4$ & $\mathrm{~B}<1 / 4$ & 0,830 & 0,860 & 0,778 & 0,801 & 0,854 & 0,789 \\
PNFI & $\geq 0,80$ & $<0,60$ & 0,809 & 0,833 & 0,766 & 0,782 & 0,825 & 0,767 \\
PCFI & $\geq 0,80$ & $<0,60$ & 0,818 & 0,844 & 0,775 & 0,791 & 0,835 & 0,775 \\
PGFI & $\geq 0,70$ & $<0,50$ & 0,731 & 0,754 & 0,691 & 0,707 & 0,747 & 0,694 \\
\hline
\end{tabular}

Note. Discrepancy function minimization method: Free-Scale Least Squares. $\chi^{2}=$ likelihood ratio chi-square statistic, $\mathrm{df}=$ degrees of freedom, $\chi^{2} / \mathrm{df}=$ relative/normed chi-square, $\mathrm{GFI}=$ Goodness-of-Fit Index, AGFI = Adjusted Goodnessof-Fit Index, NFI = Normative Fit Index, CFI = Comparative Fit Index, RFI = Relative Fit Index, RMSEA= Root Mean Square Error of Approximation, SRMR = Standardized Root Mean Square Residual, AIC = Akaike Information Criterion, $\mathrm{PR}=$ Parsimony Ratio, PNFI = Parsimonious Normative Fit Index, PCFI = Parsimonious Comparative Fit Index, PGFI = Parsimonious Goodness-of-Fit Index. Factor models: CFM-5 = correlated 5-factor model, HM-5= hierarchical model with a higher-order general factor and 5 lower-order factors, BM-5 = bifactor model with 5 specific factors and 1 general factor, CFM-6 = correlated 6-factor model, HM-6 = hierarchical model with a higher-order general factor and 6 lower-order factors, and BM- $6=$ bifactor model with 6 specific factors and 1 general factor.

Table 4. Comparison of goodness of fit with the two models with the best fit

\begin{tabular}{cccccccccc}
\hline \multirow{2}{*}{ Indices } & \multicolumn{3}{c}{ BM-5 } & \multicolumn{5}{c}{ CFM-6 } \\
\cline { 2 - 10 } & CFM-5 & HM-5 & CFM-6 & HM-6 & BM-6 & CFM-5 & HM-5 & HM-6 & BM-6 \\
\hline$\Delta \chi^{2} / \mid \Delta$ df $\mid$ & 14,738 & 13,479 & 24,918 & 17,510 & 82,215 & 6,594 & 8,9031 & 14,217 & 32,3785 \\
$\Delta$ AIC & 114,642 & 160,703 & 91,672 & 201,625 & 160,429 & 22,970 & 69,031 & 109,953 & 68,757 \\
$\Delta$ GFI & 0,009 & 0,013 & 0,007 & 0,016 & 0,012 & 0,002 & 0,006 & 0,009 & 0,005 \\
$\Delta$ AGFI & 0,011 & 0,015 & 0,009 & 0,018 & 0,015 & 0,002 & 0,006 & 0,009 & 0,006 \\
$\Delta$ NFI & 0,011 & 0,016 & 0,008 & 0,019 & 0,014 & 0,003 & 0,008 & 0,011 & 0,006 \\
$\Delta$ CFI & 0,010 & 0,015 & 0,008 & 0,018 & 0,014 & 0,002 & 0,007 & 0,010 & 0,006 \\
$\Delta$ RFI & 0,012 & 0,017 & 0,010 & 0,021 & 0,017 & 0,002 & 0,007 & 0,011 & 0,007 \\
$\Delta$ RMSEA & 0,031 & 0,039 & 0,026 & 0,045 & 0,040 & 0,005 & 0,013 & 0,019 & 0,014 \\
$\Delta$ SRMR & 0,019 & 0,026 & 0,015 & 0,030 & 0,023 & 0,004 & 0,011 & 0,015 & 0,008 \\
\hline
\end{tabular}

Note. $\Delta \chi^{2} /|\Delta \mathrm{df}|=$ quotient between the chi-square difference statistic of the 5 remaining models and BM-5 or CFM-6 and the difference in absolute value between the degrees of freedom of the 2 models being compared, $\Delta \mathrm{AIC}=$ difference between the Akaike Information Criterion of the 5 remaining models and BM-5 or CFM- $6, \Delta \mathrm{GFI}=\mathrm{di}$ fference between the Goodness of Fit Indices of BM- 5 or CFM- 6 and the 5 remaining models, $\Delta$ AGFI $=$ difference between the Adjusted Fit indices of BM- 5 or CFM- 6 and the 5 remaining models, $\Delta$ NFI $=$ difference between the Normed Fit indices of BM-5 or CFM- 6 and the 5 remaining models, $\Delta C F \mid=$ difference between the Comparative Fit indices of BM-5 or CFM- 6 and the 5 remaining models, $\mid \Delta$ RFI $\mid=$ difference between the Relative Fit indices of BM- 5 or CFM- 6 and the 5 remaining models, $\triangle \mathrm{RMSEA}=$ difference between the Root Mean Square Error of Approximation the 5 remaining models and BM-5 or CFM- 6 , and $\triangle$ SRMR $=$ difference in absolute value between the Standardized Root Mean Square Residual the 5 remaining models and BM-5 or CFM-6. 
Table 5. Internal consistency reliability, convergent validity, and discriminant validity in the models with 5 or 6 correlated factors

\begin{tabular}{cccccc}
\hline Model & Factor & ordinal $\alpha$ & $\omega$ & AVE & HTMT \\
\hline & D & 0,897 & 0,930 & 0,816 & \\
& A & 0,911 & 0,974 & 0,724 & \\
CFM-6 & L & 0,901 & 0,982 & 0,695 & 0,616 \\
& O & 0,878 & 0,961 & 0,709 & \\
& S & 0,944 & 0,982 & 0,849 & \\
& P & 0,753 & 0,821 & 0,470 & \\
CFM-5 & DA & 0,929 & 0,984 & 0,687 & \\
& L & 0,901 & 0,982 & 0,694 & \\
& O & 0,878 & 0,961 & 0,709 & 0,622 \\
& S & 0,944 & 0,982 & 0,849 & \\
\hline
\end{tabular}

Note. Models: CFM-6 = correlated 6-factor model, CFM-5 = correlated 5-factor model. Factors: D = Sexual Desire (items 1 to 2), $\mathrm{A}=$ Sexual Arousal (items 3 to 6), DA = Sexual Desire and Arousal (items 1 to 6), L= Vaginal Lubrication (items 7 to 10), $\mathrm{O}=$ Orgasm (items 11 to 13), $\mathrm{S}=$ Sexual Satisfaction (items 14 to 16), and $\mathrm{P}=\mathrm{Pain}$ during Sex (items 17 to 19). Statistics: AVE = extracted mean variance, HTMT = overall heterotrait-monotrait ratio of the correlations or overall discriminant validity index.

Table 6. Discriminant validity between factors in the correlated 5-or-6-factor models

\begin{tabular}{ccccccc}
\hline \multirow{2}{*}{ Model } & Factors & \multicolumn{5}{c}{ HTMT } \\
\cline { 2 - 6 } & F2 & F1 & F2 & F3 & F4 & F5 \\
\hline \multirow{5}{*}{ CFM-6 } & F3 & 0,657 & 0,758 & & & \\
& F4 & 0,567 & 0,754 & 0,787 & & \\
& F5 & 0,440 & 0,684 & 0,619 & 0,845 & \\
& F6 & 0,425 & 0,422 & 0,478 & 0,338 & 0.285 \\
& F2 & 0,757 & & & & \\
& F3 & 0,722 & 0,829 & & & \\
& F4 & 0,627 & 0,647 & 0,845 & & \\
& F5 & 0,404 & 0,717 & 0,338 & 0,285 & \\
\hline
\end{tabular}

Note. CFM-6 = correlated 6-factor model: F1 = Sexual Desire (items 1 to 2), F2 = Sexual Arousal (items 3 to 6), F3 $=$ Vaginal Lubrication (items 7 to 10), F4 = Orgasm (items 11 to 13), F5 = Sexual Satisfaction (items 14 to 16), and F6 = Pain during Sex (items 17 to 19). CFM-5 = correlated 5-factor model: F1 = Sexual Desire and Arousal (items 1 to 6), F2 = Vaginal Lubrication (items 7 to 10), F3 = Orgasm (items 11 to 13), F4 = Sexual Satisfaction (items 14 to 16), and F5 = Pain during Sex (items 17 to 19). HTMT = heterotrait-monotrait ratio of the correlations.

Table 7 shows the indices of the two hierarchical models (HM-5 and HM-6). It reports the omega coefficient and AVE (convergent validity) of the higher-order sub-model or direct effect of general factor on 5 or 6 hierarchical factors. On the 
other hand, it shows the hierarchical omega $(\omega \mathrm{h})$, AVE and the explained common variance $(\mathrm{ECV})$ of the lower-order sub-models. In these last three statistics, the indirect effect attributable to the general factor and the direct effect attributable to the hierarchical factor are described. The total effect (sum of both effects) and direct effect are included. The indirect and total effect is calculated for the union of the 5 or 6 hierarchical sub-models.

Table 7. Hierarchical models: omega and AVE of the higher-order sub-model, as well as hierarchical omega, AVE, and explained common variance of lower-order sub-model

\begin{tabular}{ccccccccccc}
\hline Models & \multicolumn{3}{c}{$\omega \mathrm{h}$} & & & AVE & & ECV & AVE & $\omega$ \\
\cline { 2 - 10 } GF & HF & T & GF & HF & T & GF & HF & & \\
\hline
\end{tabular}

HM-6

Higher-order sub-model of the HM-6

$0,6290,908$

$$
\text { D } \quad 0,496 \quad 0,402 \quad 0,898 \quad 0,450 \quad 0,365 \quad 0,815 \quad 0,552 \quad 0,448
$$

$\begin{array}{lcllllllll}\text { Lower- } & \mathrm{A} & \mathbf{0 , 7 5 4} & \mathbf{0 , 1 5 9} & 0,913 & 0,598 & 0,126 & 0,723 & \mathbf{0 , 8 2 6} & \mathbf{0 , 1 7 4} \\ \text { order } & \mathrm{L} & 0,633 & \mathbf{0 , 2 2 1} & 0,854 & 0,515 & 0,180 & 0,695 & 0,741 & \mathbf{0 , 2 5 9} \\ \text { sub-models } & \mathrm{O} & \mathbf{0 , 7 1 1} & \mathbf{0 , 1 6 9} & 0,879 & 0,573 & 0,136 & 0,709 & \mathbf{0 , 8 0 8} & \mathbf{0 , 1 9 2} \\ \text { of the } & \mathrm{S} & 0,550 & 0,394 & 0,944 & 0,494 & 0,355 & 0,849 & 0,582 & 0,418 \\ \text { HM-6 } & \mathrm{P} & \mathbf{0 , 1 8 6} & 0,516 & 0,703 & \mathbf{0 , 1 2 5} & 0,345 & 0,470 & \mathbf{0 , 2 6 5} & \mathbf{0 , 7 3 5} \\ & \text { Pooled } & 0,656 & 0,321 & 0,977 & 0,470 & 0,235 & 0,705 & 0,629 & 0,371\end{array}$

HM-5

Higher-order sub-model of the HM-5

$0.638 \quad 0,895$

$\begin{array}{lccccccccc} & \mathrm{DA} & 0,629 & 0,300 & 0,929 & 0,465 & 0,222 & 0,687 & 0,677 & 0,323 \\ \text { Lower- } & \mathrm{L} & 0,665 & \mathbf{0 , 1 9 0} & 0,855 & 0,540 & 0,154 & 0,694 & \mathbf{0 , 7 7 8} & \mathbf{0 , 2 2 2} \\ \text { order } & \mathrm{O} & 0,748 & \mathbf{0 , 1 3 2} & 0,879 & 0,603 & \mathbf{0 , 1 0 6} & 0,709 & \mathbf{0 , 8 5 0} & \mathbf{0 , 1 5 0} \\ \text { sub-models } & \mathrm{S} & 0,576 & 0,368 & 0,944 & 0,518 & 0,331 & 0,849 & 0,610 & 0,390 \\ \text { of the } & \mathrm{P} & \mathbf{0 , 1 9 1} & 0,511 & 0,702 & \mathbf{0 , 1 2 8} & 0,343 & \mathbf{0 , 4 7 1} & 0,272 & 0,728 \\ \text { HM-5 } & \text { Pooled } & 0,655 & 0,320 & 0,975 & 0,458 & 0,226 & 0,683 & 0,638 & 0,362\end{array}$

Note. Models: HM-6 = hierarchical model with 6 lower-order factors ( $D=$ Sexual Desire [items 1 to 2], SA = Sexual Arousal [items 3-6], L = Vaginal Lubrication [items 7-10], O = Orgasm [items 11-13]), SS = Sexual Satisfaction [items 14 to 16] and $\mathrm{P}=$ Pain during Sex [items 17 to 19]) and a higher-order general factor (sexual function), and HM-5 = hierarchical model with 5 lower-order factors (DA = Sexual Desire and Arousal [items 1 to 6], $\mathrm{L}=\mathrm{Vaginal}$ Lubrication [items 7 to 10], $\mathrm{O}=$ Orgasm [items 11 to 13], $\mathrm{S}=$ Sexual Satisfaction [items 14 to 16] and $\mathrm{P}=\mathrm{Pain}$ during Sex [items 17 to 19]) and a higher-order general factor (sexual function). Pooled = when putting together the 6 or 5 lower-order hierarchical factors. Higher-order model or direct effect of the general factor on hierarchical factors: $\omega=$ omega coefficient and AVE = extracted mean variance. Lower-order models or indirect effect of the general factor and direct effect of hierarchical factor on items: $\omega \mathrm{h}=$ hierarchical omega, AVE = extracted mean variance and $\mathrm{ECV}=$ explained common variance attributable to the indirect effect of the general factor (GF) and attributable to the direct effect of the hierarchical factor (HF), as well as the sum of both effects or total effect (T). Values that show an excessive or poor contribution are highlighted in bold.

Table 8 shows the indices corresponding to the two bifactor models (BM-5 and BM-6). The direct effect due to the specific factor and the direct effect due to the general factor on each domain of content are also detailed. The total effect or sum of both effects is included. Furthermore, these two effects are calculated for the entire 19 items. 
Table 8. Bifactor models: indices for assessing the contribution of the general and specific factor in each content domain and convergent validity

\begin{tabular}{cccccccc}
\hline \multicolumn{2}{c}{$\begin{array}{c}\text { Models } \\
\text { SF }\end{array}$} & \multicolumn{2}{c}{$\omega_{\mathrm{h}}$} & \multicolumn{2}{c}{ AVE } & \multicolumn{2}{c}{ ECV } \\
\hline BM-6 & D & 0,410 & 0,494 & 0,377 & 0,449 & 0,457 & 0,543 \\
& A & $\mathbf{0 , 1 5 9}$ & $\mathbf{0 , 7 5 4}$ & 0,127 & 0,597 & $\mathbf{0 , 1 7 5}$ & $\mathbf{0 , 8 2 5}$ \\
& L & $\mathbf{0 , 2 3 9}$ & 0,672 & 0,207 & 0,518 & $\mathbf{0 , 2 8 5}$ & $\mathbf{0 , 7 1 5}$ \\
& O & $\mathbf{0 , 1 7 2}$ & $\mathbf{0 , 7 1 2}$ & 0,147 & 0,574 & $\mathbf{0 , 2 0 4}$ & $\mathbf{0 , 7 9 6}$ \\
BM-5 & 0,395 & 0,552 & 0,362 & 0,497 & 0,421 & 0,579 \\
& S & $\mathbf{0 , 7 1 7}$ & $\mathbf{0 , 1 2 6}$ & 0,533 & $\mathbf{0 , 1 1 7}$ & $\mathbf{0 , 8 2 1}$ & $\mathbf{0 , 1 7 9}$ \\
& DA & 0,305 & 0,631 & 0,246 & 0,470 & 0,344 & 0,656 \\
& L & $\mathbf{0 , 2 1 2}$ & $\mathbf{0 , 7 0 1}$ & 0,191 & 0,540 & $\mathbf{0 , 2 6 1}$ & $\mathbf{0 , 7 3 9}$ \\
& O & $\mathbf{0 , 1 4 0}$ & $\mathbf{0 , 7 4 6}$ & $\mathbf{0 , 1 2 3}$ & 0,600 & $\mathbf{0 , 1 7 0}$ & $\mathbf{0 , 8 3 0}$ \\
& S & 0,371 & 0,576 & 0,341 & 0,519 & 0,396 & 0,604 \\
& P & $\mathbf{0 , 7 2 0}$ & $\mathbf{0 , 1 5 6}$ & 0,622 & $\mathbf{0 , 1 2 9}$ & $\mathbf{0 , 8 2 8}$ & $\mathbf{0 , 1 7 2}$ \\
& SexF & 0,349 & 0,631 & 0,289 & 0,459 & 0,387 & 0,613 \\
\hline
\end{tabular}

Note. Models: BM-6 = bifactor model with 6 specific factors and 1 general factor, BF-5 = bifactor model with 5 specific factors and 1 general factor. Content domains: $\mathrm{D}=$ Sexual Desire (items 1 to 2), $\mathrm{A}=$ Sexual Arousal (items 3 to 6), $\mathrm{DA}=$ Sexual Desire and Arousal (items 1 to 6), $\mathrm{L}=$ Vaginal Lubrication (items 7 to 10 ), $\mathrm{O}=$ Orgasm (items 11 to 13 ), $\mathrm{S}=$ Sexual Satisfaction (items 14 to 16 ) and $\mathrm{P}=$ Pain during $\mathrm{Sex}$ (items 17 to 19 ) and $\mathrm{SexF}=$ sexual function (items 1 to 19). $\mathrm{SF}=$ specific factor and $\mathrm{GF}=$ general factor. Statistics: $\omega \mathrm{h}=$ ordinal hierarchical omega coefficient, $\mathrm{AVE}=$ extracted mean variance, and $\mathrm{ECV}=$ explained common variance. Values that show an excessive or poor contribution are highlighted in bold.

Among the six models specified, the bifactor model with 5 specific factors and 1 general factor (BM-5) had the best fit indices. The fit values of seven out of the eight contemplated indices were close and the SRMR had an acceptable fit value. Its parsimony was high $(\mathrm{PR}=0.78>0.75)$ and the relationship between fit and parsimony was acceptable (Table 3). Its goodness of fit was greater than the one from the other models based on $\Delta \chi^{2} / \mid \Delta \mathrm{df}\lceil$ and $\Delta \mathrm{AIC}$. The greatest difference was the bifactor model with 6 specific factors (BM-6) and the smallest difference was with the 6-correlated factors (CFM-6) (Table 4). All measurement weights were significantly non-null (Figure 1). In the analysis of the 19 items or union of the five content domains, the contribution of the general factor was greater $(0.70>\omega \mathrm{h}=0.63$ and $\mathrm{ECV}=0.61>0.30$, and $0.70>\mathrm{AVE}=0.46>0.08)$ than the one of the 5 specific factors $(0.70>\omega \mathrm{h}=0.35$ and $\mathrm{ECV}=0.39>0.30$, and $0.70>\mathrm{AVE}=0.29>0.08)$, although without being excessive. Nevertheless, the contribution of the general factor was excessive compared to the specific factor, which was poor in both the three items of vaginal lubrication and in the three items of orgasm. On the contrary, the contribution of the specific factor was excessive compared to that of the general factor, which was poor in the 3 items of pain during sex (Table 8).

In the 6-factor model (CFM-6), the fit values of 5 out of the 8 indices were close, and the remaining three indices were acceptable. This model showed greater 
Figure 1. Standardized measurement weights and percentages of explained variance in the bifactor model with a general factor and 5 specific factors (BM-5)

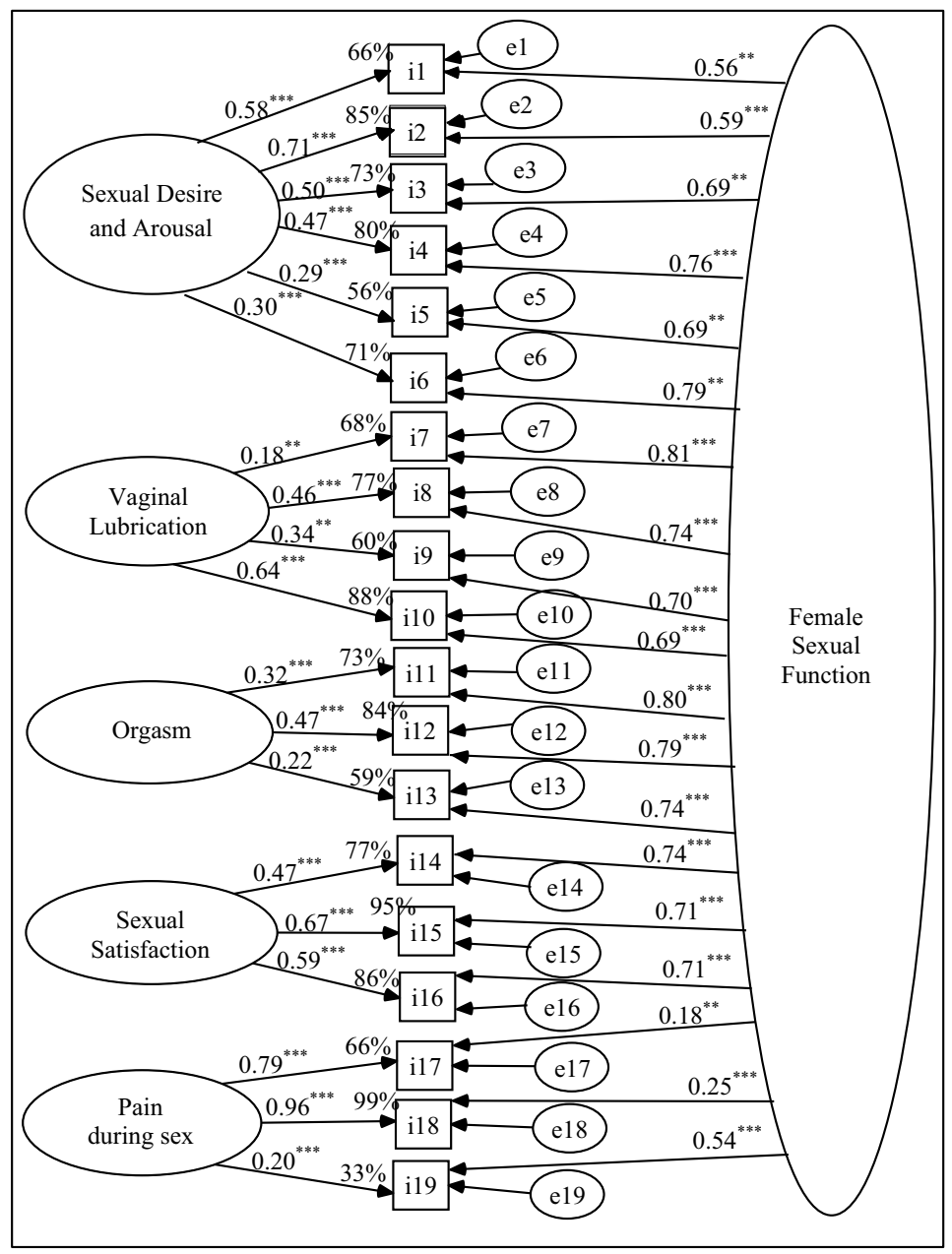

Note. Method for the point estimation of parameters: Scale-free least square. Bootstrap method to estimate standard errors and the significance of parameters: Bias-corrected percentile method, using 2000 bootstrap samples. Twotailed significance: $* * * p$-value $\leq 0.001$, and $* * p$-value $\leq 0.01$. Items: Over the past 4 weeks, i1) how often did you feel sexual desire or interest?, i2) how would you rate your level (degree) of sexual desire or interest?, i3) did you feel sexually aroused ("turned on") during sexual activity or intercourse?, i4) how would you rate your level of sexual arousal ("turn on") during sexual activity or intercourse?, i5) how confident were you about becoming sexually aroused during sexual activity or intercourse?, i6) how often have you been satisfied with your arousal (excitement) during sexual activity or intercourse?, i7) how often did you become lubricated ("wet") during sexual activity or intercourse?, i8) how difficult was it to become lubricated ("wet") during sexual activity or intercourse?, i9) how often did you maintain your lubrication ("wetness") until completion of sexual activity or intercourse?, i10) how difficult was it to maintain your lubrication ("wetness") until completion of sexual activity or intercourse?, i11) when you had sexual stimulation or intercourse, how often did you reach orgasm (climax)?, i12) when you had sexual stimulation or intercourse, how difficult was it for you to reach orgasm (climax)?, i13) how satisfied were you with your ability to reach orgasm (climax) during sexual activity or intercourse?, i14) how satisfied have you been with the amount of emotional closeness during sexual activity between you and your partner?, i15) how satisfied have you been with your sexual relationship with your partner?, i16) how satisfied have you been with your overall sexual life?, i17) how often did you experience discomfort or pain during vaginal penetration?, i18) how often did you experience discomfort or pain following vaginal penetration?, and i19) how would you rate your level (degree) of discomfort or pain during or following vaginal penetration? 
parsimony than the bifactor model with 5 specific factors (BM-5), as well as a better relationship between fit and parsimony (Table 3). Its goodness of fit was better than the bifactor model with 6 specific factors (BM-6) and the two hierarchical models (HM-5 and HM-6) by at least 4 indices: $\Delta \chi^{2} /|\Delta \mathrm{df}|, \Delta \mathrm{AIC}, \Delta \mathrm{RMSEA}$, and $\triangle$ RMSEA. The goodness of fit between the two correlated-factor models (CFM-6 and CFM-5) was very similar, although the index $|\chi 2 / \Delta \mathrm{df}|$ showed that the 6-factor model (CFM-6) had a better fit than the 5-factor model (CFM-5) (Table 4). The 6 factors of CFM-6 presented all their measurement weights significantly non-null (Figure 2), as well as convergent $(\lambda>0.50, \omega>0.70$, and AVE $\geq 0.54$ for 2 indicators, 0.44 for 3 indicators, and 0.37 for 4 indicators) and discriminant validity (HTMR $<0.85$ ) (Table 5 and 6). The internal consistency reliability values of the vaginal lubrication, sexual satisfaction and sexual arousal factors were excellent (ordinal $\alpha \geq$ 0.90 ), the ones of the sexual desire and orgasm factors were good (ordinal $\alpha \geq 0.80$ ), and those of the pain during sex factor was acceptable (ordinal $\alpha \geq 0.70$ ) (Table 5). The consistency of the 19 items was excellent (ordinal $\alpha=0.94$ ). These properties were also fulfilled in the correlated 5 -factor model (Tables 5 and 6).

Figure 2. Standardized measurement weights and percentages of explained variance in the correlated 6-factor model (CFM-6)

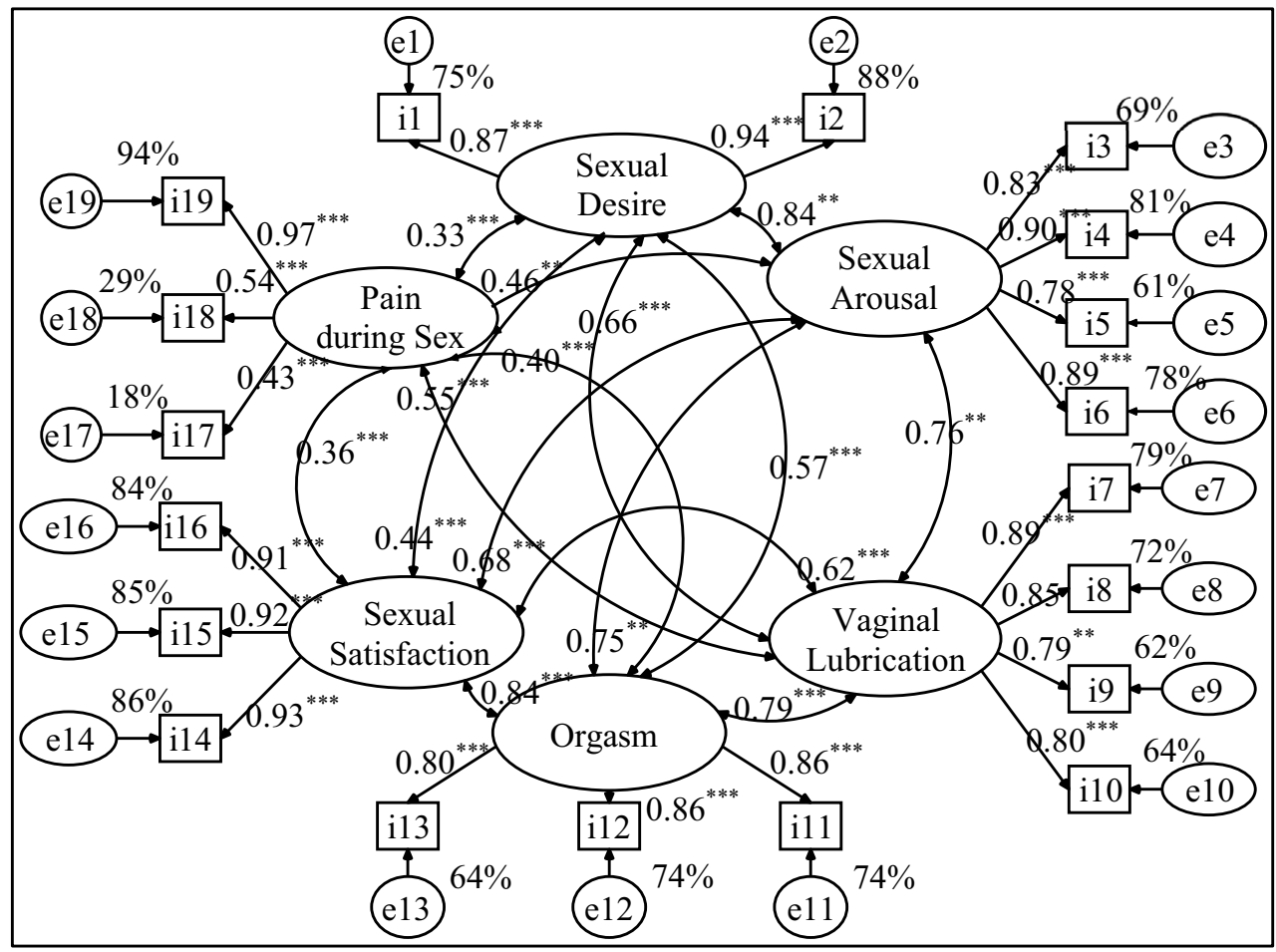

Note. Method for the point estimation of parameters: Scale-free least square. Method for estimating standard errors and testing the significance of the parameters: Bias-corrected percentile bootstrap, using 2000 bootstrap samples. Two-tailed significance: $* * *$ p-value $\leq 0.001$, and $* *$ p-value $\leq 0.01$. 
Finally, the models with the worst fit were the two hierarchical models (HM-5 and HM-6) (Tables 3 and 4). The higher-order sub-model (direct effect of general factor on 5 or 6 hierarchical factors) in HM-5 and HM-6 had convergent validity. The lowerorder sub-model (indirect effect of general factor and direct effect of hierarchical factor on items) in HM-5 and HM-6 showed also convergent validity and an important contribution both the general factor and the hierarchical factors in the conjunct of 19 items. The three items of sexual satisfaction, as well as the two items of sexual desire (HM-5) and the six items of sexual desire and arousal (HM-6) had greater weight of the general factor than hierarchical factors. However, the general factor had excessive contribution to the detriment of the hierarchical factors in the four items of sexual arousal, in the three items of orgasm, and in the four items of vaginal lubrication. On the opposite side, the hierarchical factor had an excessive contribution to the detriment of the general factor in the three items of pain during sex (Table 7).

\section{Distributions of scores on the general factor and specific factors}

Considering that the CFM-6 showed the best properties, it was decided to calculate the scores of the six factors and a total score. Only the distribution of the sexual desire factor showed symmetry and was adjusted to a normal distribution by the D'Agostino-Pearson $\mathrm{K}^{2}$ test $\left(\mathrm{K}^{2}=3.70\right.$, right-tailed $\left.\mathrm{p}=0.157\right)$. The other distributions did not follow a normal distribution, because they presented negative asymmetry or bias towards high scores with long tails to the left (Table 9).

Table 9. Descriptive statistics and normality tests for the FSFI and its 6 factors.

\begin{tabular}{cccccccc}
\hline Statistics & FSFI & D & A & L & O & S & P \\
\hline Rosen et al.'s (2000) scoring method & & & & & \\
\hline Min & 8,8 & 1,2 & 1,2 & 1,2 & 1,2 & 1,2 & 1,6 \\
Max & 36 & 6 & 6 & 6 & 6 & 6 & 6 \\
M & 27,408 & 3,631 & 4,272 & 4,972 & 4,821 & 5,007 & 4,706 \\
SDev & 4,998 & 1,127 & 1,148 & 1,006 & 1,153 & 1,155 & 1,286 \\
Z $_{\text {Sk }}$ & $-4,116$ & 0,336 & $-3,204$ & $-6,318$ & $-5,932$ & $-8,939$ & $-3,406$ \\
$Z_{K}$ & 0,213 & $-1,544$ & $-1,946$ & 1,015 & 0,163 & 4,813 & $-3,992$ \\
K & 16,953 & 0,709 & 11,210 & 40,180 & 35,200 & 85,693 & 15,586 \\
p-value & $<0,001$ & 0,702 & 0,004 & $<0,001$ & $<0,001$ & $<0,001$ & $<0,001$ \\
KSL & 0,066 & 0,154 & 0,126 & 0,161 & 0,17 & 0,195 & 0,199 \\
p-value & 0,006 & $<0,001$ & $<0,001$ & $<0,001$ & $<0,001$ & $<0,001$ & $<0,001$ \\
P10 & 19,93 & 2,4 & 2,7 & 3,6 & 2,92 & 3,32 & 2,8 \\
P20 & 22,96 & 2,4 & 3,18 & 4,2 & 4 & 4,24 & 3,2 \\
P25 & 24,025 & 3 & 3,6 & 4,2 & 4 & 4,5 & 3,6 \\
P30 & 25,49 & 3 & 3,6 & 4,5 & 4,4 & 4,8 & 4 \\
P40 & 26,8 & 3,6 & 4,2 & 4,8 & 4,8 & 4,8 & 4,4 \\
P50 & 28,1 & 3,6 & 4,5 & 5,1 & 5,2 & 5,2 & 4,8 \\
P60 & 29,28 & 3,6 & 4,8 & 5,4 & 5,6 & 5,6 & 5,6 \\
P70 & 30,6 & 4,2 & 5,1 & 5,7 & 5,6 & 6 & 6 \\
P75 & 31,2 & 4,2 & 5,1 & 6 & 6 & 6 & 6 \\
\hline
\end{tabular}




\begin{tabular}{cccccccc}
\hline Statistics & FSFI & D & A & L & O & S & P \\
\hline \multicolumn{2}{l}{ Rosen et al.'s (2000) scoring method } & & & & & \\
\hline P80 & 32 & 4,8 & 5,4 & 6 & 6 & 6 & 6 \\
P90 & 33,37 & 5,4 & 5,7 & 6 & 6 & 6 & 6
\end{tabular}

Homogeneous score range 1 to 5 or average transformation for FSFI and its 6 factors

$\begin{array}{cccccccc}\text { Min } & 1,211 & 1 & 1 & 1 & 1 & 1 & 1,333 \\ \operatorname{Max} & 5 & 5 & 5 & 5 & 5 & 5 & 5 \\ \mathrm{M} & 3,853 & 3,026 & 3,560 & 4,143 & 4,017 & 4,173 & 3,922 \\ \mathrm{SD} & 0,703 & 0,939 & 0,956 & 0,839 & 0,961 & 0,963 & 1,072 \\ \mathrm{Q}_{1} & 3,368 & 2,5 & 3 & 3,5 & 3,333 & 3,750 & 3 \\ \mathrm{Q}_{2} & 3,947 & 3 & 3,75 & 4,25 & 4,333 & 4,333 & 4 \\ \mathrm{Q}_{3} & 4,421 & 3,5 & 4,25 & 5 & 5 & 5 & 5\end{array}$

Note. Rosen et al. (2000) scoring method: rank to 1.2 to 6 for factors and 7.2 to 36 for FSFI in sexually active women within the past 4 weeks. Homogeneous score range 1 to 5 or average transformation for FSFI and its factors: FSFI $=$ Female Sexual Function Index $=\operatorname{Sum}(\mathrm{I} 1$ to I19) $/ 19, \mathrm{D}=$ Sexual Desire $=\operatorname{Sum}(\mathrm{I} 1$ to I2) $/ 2, \mathrm{~A}=\mathrm{Sexual}$ Arousal $=$ $\operatorname{Sum}(\mathrm{I} 3$ to I6) $/ 4, \mathrm{~L}=$ Vaginal Lubrication $=\operatorname{Sum}(\mathrm{I} 7$ to $\mathrm{I} 10) / 4, \mathrm{O}=\operatorname{Orgasm}=\mathrm{Sum}(\mathrm{I} 11$ to I13) $/ 3, \mathrm{~S}=\mathrm{Sexual}$ Satisfaction $=\operatorname{Sum}(I 14$ to I16)/3, and $\mathrm{P}=$ Pain during $\operatorname{Sex}=\operatorname{Sum}(\mathrm{I} 17$ to I19)/3. Statistics: Min $=$ sample minimum value, $\mathrm{Max}=$ sample maximum value, $\mathrm{M}=$ sample arithmetic mean, $\mathrm{SDev}=$ sample standard deviation, $\mathrm{Z}_{\mathrm{Sk}}=$ standardized value of sample coefficient of skewness based on third central moment, $Z_{K}=$ standardized value of sample excess kurtosis, $\mathrm{K}^{2}$ = D'Agostino-Pearson's test statistics, $\mathrm{p}$-value = probability value under null hypothesis of normal distribution, KSL = Kolmogorov-Smirnov test statistics, p-value = probability value under null hypothesis of normal distribution using Lilliefors's correction, $\mathrm{P} 10$ to $\mathrm{P} 90=$ sample percentile values, and $\mathrm{Q}_{1}$ to $\mathrm{Q}_{3}=$ sample quartiles.

When comparing the central tendency of the six factors using the Friedman test, there was a significant difference $\left(\chi^{2}[5]=397.18\right.$, right-tail $p$-value $\left.<0.001\right)$. There was a strong effect of the type of symptoms on FSD $(\mathrm{W}=0.29)$. When making pairwise comparisons with the Dunn's test, the MRof orgasm $(M R=3.96)$ and pain during sex $(M R=3.84)$ were statistically equivalent $(Z=0.75$, adjusted 2-tailed $\mathrm{p}$-value $>0.999)$. In the same way, the mean range of vaginal lubrication $(\mathrm{RM}=4.14)$ was equivalent to the mean ranges of orgasm $(Z=1.12$, adjusted $p$-value $>0.999)$, sexual satisfaction $(M R=4.39)(Z=-1.56$, adjusted 2-tailed $p$-value $=0.715)$, and pain during sex $(Z=1.87$, adjusted 2-tailed $p$-value $=0.369)$. In the remaining 17 comparisons, there were significant differences (adjusted 2-tailed p-value $<0.050$ ). The mean ranges of these four factors were higher than the mean ranges of sexual desire $(M R=1.87)$ and sexual arousal $(M R=2.80)$. The MR of sexual desire was significantly the lowest (Table 9).

A more intuitive way of scoring the FSFI total score and the six factors is through an average scoring rule. Items are added and then divided by the number of items. This rule allows an absolute interpretation of the scores. By dividing the continuous range into five intervals of constant amplitude ([maximum value (5) minimum value (1)]/number of values on the item response scale $(5)=4 / 5=0.8$ ), the scores on the FSFI and the six factors can be interpreted as corresponding with the five response categories of the items. The scores (1-1.79) correspond to the first response "never or almost never", which show very low functionality. Scores from 1.80-2.59 correspond to the second response "less than half the time" and show low functionality. Scores from 2.6-3.39 correspond to the third response "half the time" and indicate medium functionality. Scores from 3.4-4.19 correspond to the fourth response "more than half the time" and show high functionality. Finally, scores from 
4.2-5 correspond to the fifth response "almost always or always" and show very high functionality. To convert the scores obtained in the range from 1.2-6 to a range from $1-5$, you must multiply them by $5 / 6$. For the FSFI total score, you must first divide it by six and then multiply it by $5 / 6$.

Using the median as the central tendency statistic, the middle values of the FSFI total score $(\mathrm{Mdn}=3.95)$, as well as the factors of sexual arousal $(\mathrm{Mdn}=3.75)$ and pain during sex $(\mathrm{Mdn}=4)$ corresponded to a high functionality (from 3.4 to 4.19$)$. The medians of the factors of vaginal lubrication ( $\mathrm{Mdn}=4.25)$, orgasm $(\mathrm{Mdn}=4.33)$ and sexual satisfaction $(\mathrm{Mdn}=4.33$ ) corresponded to very high functionality (from 4.2 to $5)$. However, the middle value of sexual desire factor $(\mathrm{Mdn}=3)$ was in the interval of medium functionality (2.6-3.39) (Table 9. Of the 272 women, we found very low sexual functionality in $0.7 \%$, low in $4.4 \%$, medium in $20.6 \%$, high in $37.5 \%$ and very high in the $36.8 \%$. These percentages clearly show a profile with an increasing trend (higher percentage the higher the index value) and negative skewness (long tail to left).

\section{Prevalence of FSD}

Using the cutoff point of 26.55 for the FSFI total score (Wiegel et al., 2005), there were 103 cases of FSD, which represents a prevalence of $37.9 \%$ (95\% CI: 32\%, $43.8 \%$ ). The value 3.69 (which is equivalent to the value of 26.55 ranging from 1 to 5) corresponds to the sample percentile $36(95 \% \mathrm{CI}: 30-42)$. By the binomial test, the null hypothesis of a prevalence of at least $40 \%$ (one-tailed p-value $=0.257$ ) was maintained. In the total sample of 441 patients, which included women without sexual activity in the last four weeks (FSFI total score range from 1.2 to $6<26.55$ ), the prevalence was $61.7 \%$ (95\% CI: 57\%, 66.4\%). Using the binomial test, the null hypothesis of a prevalence of at least $60 \%$ (one-tailed $p$-value $=0.252$ ) was maintained.

\section{Discussion}

Our first objective was to check the hypothetical models of 5 and 6 factors proposed for the FSFI in the 19-item format. Besides the specification of a hierarchical model made by Bartula \& Sherman ${ }^{(17)}$, only the correlated-factor models had been previously contrasted. In the present study, hierarchical models and bifactor models were specified, justifying the calculation of a total score and specific factor scores $^{(18,20)}$. However, the contrast of the single-factor model was not presented since the multifactorial models did not suggest it, either due to the lack of discrimination between their content domains or due to the excessive weight of the general factor in all content domains. It should be noted that the fit indices of the single-factor model were poor, just like it has been shown in previous studies ${ }^{(17)}$.

The bifactor model of 5 specific factors and one general factor (BM-5) obtained the best fit, followed by the CFM-6, but it was outperformed by the last one in parsimony and its relationship between fit and parsimony. This is not an unusual result since the bifactor model is more saturated or less parsimonious than the correlated and hierarchical factor models, hence it is necessary to check the contribution of the different factors ${ }^{(21)}$. The indices (omega, AVE and ECV) showed that the general factor had an important influence in the items of orgasm and vaginal lubrication in detriment of the specific factor, and poor influence in the pain during sex items. In 
the 6-factor model, when separating the contents of sexual desire and sexual arousal, the general factor had an important impact on the sexual arousal items in detriment of the specific factor. This data was also reproduced by the hierarchical model, but these models ( 5 or 6 hierarchical factors) showed the worst fit indices. However, the correlated 6-factor model did not have problems of convergent validity and the items were better explained by the factor they configure than by other factors. Therefore, this model proved to be more adequate for the data and it showed a good fit.

Stating that the correlated 6-factor model is the one that best represents the interrelationship between the items, the calculation of a total score is not theoretically justified. In this setting, the calculation becomes merely practical, based on its usefulness, such as having a cut-off point to diagnose FSD, and on the positive interrelationship between the 6 factors.

Among all the factors, pain during sex had the lowest correlations. Consistent with these data found in the correlated-factor model, the specific or hierarchical factor of pain during sex showed an inverse behavior to the rest of the factors in the bifactor and hierarchical factor models. Its effect on the items was excessive to the detriment of the general factor, where the general factor had a greater effect than the specific or hierarchical factor in the other content domains. This indicates that among women with cancer, pain during sex is the factor least related to the other FSD symptoms. The same result was previously obtained in a study made in Spanish women with pelvic floor disorders in which they reproduced the correlated 6-factor model with good discriminant validity between the factors, using principal component analysis and showing that the pain during sex factor had the lowest correlation with the other factors ${ }^{(16)}$. Additionally, Witting et al. ${ }^{(22)}$ and Vallejo-Medina et al. ${ }^{(15)}$, they obtained a good fit for the correlated 6-factor model using confirmatory analysis reporting that the pain during sex factor had the lowest correlation. On the other hand, Bartula \& Sherman ${ }^{(17)}$ obtained a good fit for the correlated 6-factor model without problems of convergent and discriminant validity compared to a worse fit of the hierarchical model. In this last study, orgasm was the least related factor, whereas the study made by Baser et al ${ }^{(9)}$ showed that it was the vaginal lubrication factor. Therefore, pain during sex is not always the least related factor in women with cancer. These variations between studies in women with cancer could be due to side effects of the applied treatment (vaginal dryness, inhibition of the response to orgasm or sensitivity to pain), to different subjective criteria (mediated by culture) to assess sexual functions or simply for idiosyncratic characteristics of each sample.

The second objective was to verify the internal consistency reliability of the FSFI total score and its factors. According to the results of previous research in women with cancer ${ }^{(9,12,13,17)}$, the FSFI had an excellent internal consistency and the factors had values that ranged from excellent to good, except for pain during sex which had an acceptable internal consistency. In this study, pain during sex did not only showed the least interrelation in the set of symptoms of FSD, but also the internally variants of its symptoms were less consistent compared to the rest of the factors. It should be emphasized that the factor with the lowest internal consistency varies between studies where the 6-factor model has been reproduced. This is the case of the study made by Bartula \& Sherman ${ }^{(17)}$ where vaginal lubrication had the lowest internal consistency, while in Sánchez-Sánchez et al. ${ }^{(16)}$ study it was orgasm, in Vallejo-Medina et al. ${ }^{(15)}$ study were sexual desire and sexual arousal, in Witting et al. ${ }^{(22)}$ it was sexual desire. 
The third objective was to describe the distribution of the FSFI and its factors. Except for the sexual desire factor scores, the rest of the scores did not follow a normal distribution and showed skewness with a long tail towards the left. With the FSFI, this type of bias appears in both the non-clinical and clinical setting ${ }^{(16,22)}$, hence the cut-off points for diagnosing FSD is close to the pole of sexual functionality ${ }^{(12)}$. The cutoff point of 26.55 in the range of $7.2-36$ corresponds to 3.69 in the range of $1-5$. This is a value close to the midpoint $(3.8)$ of the fourth interval $(3.4,4.2)$ that corresponds to a high sexual functionality.

Patients reported high sexual functionality. The median shows that these women report high functionality in sexual arousal and a very high functionality in lubrication, orgasm and sexual satisfaction. Only the middle value (median) and the average value (arithmetic mean) in sexual desire factor, which match, showed a medium functionality. The mean FSFI score in the present study $(\mathrm{M}=27.41$, biascorrected and accelerated bootstrap 95\% CI: 26.78, 27.99) was clearly higher than that reported in women treated for breast cancer $(\mathrm{M}=19.58,95 \% \mathrm{CI} 17.64-21.53)^{(1)}$, and even higher than the average obtained from a sample of the Spanish general population $(\mathrm{M}=25.7,95 \% \mathrm{CI}: 24.84,26.56)^{(16)}$, but lower than the reported in the Colombian general population ( $\mathrm{M}=29.46,95 \% \mathrm{CI}: 29.11,29.82)^{(15)}$. Therefore, the women that participated in this study report a sexual functionality value within a range of the general population parameter.

It should be noted that the analyzed sample consisted mostly of young women $(85 \%)$ and middle-aged women $(15 \%)$. Most of them had a low income $(88 \%)$, public health insurance, and had a middle school level of schooling. All of them had been recently diagnosed with breast cancer (maximum of three months before the questionnaire), were about to start their cancer treatment and reported having sexual intercourse with their partners. Our sample is more similar to the general population than to the clinical population regarding sexual side effects of cancer treatments or natural history of the disease. Compared to the excluded patients, they had earlystage cancer and more of them lived with their sexual partner.

The fourth objective was to estimate the prevalence of FSD in the sample. The prevalence of FSD was $37.9 \%$, which corresponds to the one found in the general population ${ }^{(22-24)}$ and close to the one from previous studies of women with cancer $(>60 \%)^{(1)}$. This result is expected since the participants of this study had recent diagnosis of breast cancer. Hence, the prevalence of FSD in the general population of breast cancer patients cannot be calculated. Among the limitations of the study was the use of incidental non-probability sampling, so conclusions should be taken with caution. There is no paired short-term data (days or weeks) per patient to assess the temporal reliability of FSFI and the stability of the factor structure. The Spanish translation of FSFI was assumed to be appropriate for Mexican women given the properties of the questionnaire in Chile and other Spanish-speaking countries. Finally, the DSM-V, known as the gold standard for clinical diagnosis ${ }^{(25)}$, was not used to diagnose sexual dysfunction, hypoactive sexual desire disorder, sexual arousal disorder, orgasmic disorder, and dyspareunia, in order to determine a cut-off value that optimizes diagnostic sensitivity and specificity.

In conclusion, in this sample of young Mexican women with breast cancer in the basal phase of treatment who had sexual intercourse in the 4 weeks prior to the survey, the correlated 6-factor model for the 19-item FSFI presented the best properties when considering goodness of fit, parsimony, as well as the convergent 
and discriminant validity of the factors. Its internal consistency reliability is excellent, and its factor reliabilities vary from excellent to good, with the exception of pain during sex, which was acceptable. The FSFI total score and factor distributions did not follow the normal probability law. They presented bias towards the left tail with the concentration of the scores in the high values of sexual functionality. The only exception was the distribution of the sexual desire factor which was symmetric. The measures of central tendency reflect a report of high sexual functionality. With the cutoff value of 26.55, approximately 4 out of 10 women had FSD, which is similar to the prevalence in the general population.

\section{References}

1. Maiorino MI, Chiodini P, Bellastella G, Giugliano D. Esposito K. Sexual dysfunction in women with cancer: a systematic review with meta-analysis of studies using the Female Sexual Function Index. Endocrine 2016;54:329-41. https://doi.org/10.1007/s12020-0150812-6.

2. Champion VL, Wagner LI, Monahan PO, et al. Comparison of younger and older breast cancer survivors and age-matched controls on specific and overall quality of life domains. Cancer 2014; 120:2237-46. https://doi.org/10.1002/cncr.28737.

3. Rana P, Ratcliffe J, Sussman J, Forbes M, Levine M, Hodgson N, Schumacher U. Young women with breast cancer: Needs and experiences. Cogent Med 2017;4:1-11. https://doi. org/10.1080/2331205x.2017.1278836.

4. Kedde H, Van De Wiel HBM, Weijmar Schultz WCM, Wijsen C. Sexual dysfunction in young women with breast cancer. Support Care Cancer 2013;21:271280. https://doi. org/10.1007/s00520-012-1521-9.

5. Lee M, Kim YH, Jeon MJ. Risk factors for negative impacts on sexual activity and function in younger breast cancer survivors. Psychooncology 2015; 24: 1097-103. https://doi.org/10.1002/pon.3772.

6. Ljungman L, Ahlgren J, Petersson LM, Flynn KE, Weinfurt K, Gorman JR et al. Sexual dysfunction and reproductive concerns in young women with breast cancer: Type, prevalence, and predictors of problems. Psychooncology 2018;27:2770-7. https://doi. org $/ 10.1002 /$ pon. 4886

7. Reese JB, Sorice K, Beach MC, Porter LS, Tulsky JA, Daly MB, et al. Patient-provider communication about sexual concerns in cancer: a systematic review. J Cancer Surviv 2017;11:175-88. https://doi.org/10.1007/s11764-016-0577-9.

8. Bober SL, Kingsberg SA, Faubion SS. Sexual function after cancer: paying the price of survivorship. Climacteric 2019;22:558-64. https://doi.org/10.1080/13697137.2019.1606 796.

9. Baser RE, Li Y, Carter J. Psychometric validation of the female sexual function index (FSFI) in cancer survivors. Cancer 2012;118: 4606-18. https://doi.org/10.1002/ cncr.26739

10. Rosen R, Brown C, Heiman J, et al. (2000). The female sexual function index (FSFI): A multidimensional self-report instrument for the assessment of female sexual function. J Sex Marital Ther 2000;26:191-208. https://doi.org/10.1080/009262300278597.

11. American Psychiatric Association. Diagnostic and Statistical Manual of Mental Disorders, 4th Edition, Text Revision. Washington, DC: American Psychiatric Association; 2000. 
12. Wiegel M, Meston C, Rosen R. The Female Sexual Function Index (FSFI): Crossvalidation and development of clinical cutoff scores. J Sex Marital Ther 2005;31:1-20. https://doi.org/10.1080/00926230590475206.

13. Bartula I, Sherman KA. Development and validation of the Female Sexual Function Index adaptation for breast cancer patients (FSFI-BC). Breast Cancer Res Treat 2015;152:477-88. https://doi.org/10.1007/s10549-015-3499-8.

14. Blümel JE, Binfa L, Cataldo P, Carrasco A, Izaguirre H, Sarrá S (2004). Índice de Función Sexual Femenina: un test para evaluar la sexualidad de la mujer. Rev Chil Obstet Ginecol 2004;34:286-92. https://doi.org/10.4067/s0717-75262004000200006.

15. Vallejo-Medina P, Pérez-Durán C, Saavedra-Roa A. Translation, adaptation, and preliminary validation of the Female Sexual Function Index into Spanish (Colombia). Arch Sex Behav 2018;47:797-810. https://doi.org/10.1007/s10508-017-0976-7.

16. Sánchez-Sánchez B, Navarro-Brazález B, Arranz-Martín B, Sánchez-Méndez O, de la Rosa-Díaz I, Torres-Lacomba M. The female sexual function index: Transculturally adaptation and psychometric validation in Spanish women. Int J Environ Res Public Health 2020;17:1-13. https://doi.org/10.3390/ijerph17030994.

17. Bartula I, Sherman KA. The Female Sexual Functioning Index (FSFI): evaluation of acceptability, reliability, and validity in women with breast cancer. Support Care Cancer 2015;23:2633-41. https://doi.org/10.1007/s00520-015-2623-y.

18. Mansolf M, Reise SP. When and why the second-order and bifactor models are distinguishable. Intelligence2017;61:120-29.https://doi.org/10.1016/j.intell.2017.01.012.

19. Neijenhuijs KI, Hooghiemstra N, Holtmaat K, et al. The Female Sexual Function Index (FSFI)-A systematic review of measurement properties. J Sex Med 2019;16:640-660. https://doi.org/10.1016/j.jsxm.2019.03.001.

20. Reise SP. The rediscovery of bifactor measurement models. Multivar Behav Res 2012;47:667-96. https://doi.org/10.1080/00273171.2012.715555

21. Rodriguez A, Reise SP, Haviland MG. Evaluating bifactor models: Calculating and interpreting statistical indices. Psychol Methods 2016;21:137-50. https://doi.org/10.1037/ met0000045.

22. Witting K, Santtila P, Jern P, et al. Evaluation of the Female Sexual Function Index in a population based sample from Finland. Arch Sex Behav 2008;37:912-24. https://doi. org/10.1007/s10508-007-9287-8

23. Muñoz, AP, Camacho PA. Prevalencia y factores de riesgo de la disfunción sexual femenina: revisión sistemática. Rev Chil Obstet Ginecol 2016;81:168-80. https://doi. org/10.4067/s0717-75262016000300002.

24. Sidi H, Abdullah N, Puteh SEW, Midin, M. The female sexual function index (FSFI): Validation of the Malay version. J Sex Med 2007;4:1642-54 https://doi.org/10.1111/ j.1743-6109.2007.00476.x.

25. First M, Williams J, Karg R, Spitzer R. Structured clinical interview for DSM-5 disorders, clinician version (SCID-5-CV). Washington, DC: American Psychiatric Association, 2016. 